\title{
Testing Joints of Air and Vapour Barriers, Do We Use Relevant Testing Methods?
}

\author{
Eva B. Møller ${ }^{1}$ and Torben V. Rasmussen ${ }^{2}$ \\ ${ }^{1}$ Department of Civil Engineering, Technical University of Denmark, Brovej 118, 2800 Kgs. Lyngby, \\ Denmark, ebmo@byg.dtu.dk \\ ${ }^{2}$ Danish Building Research Institute, Aalborg University Copenhagen, A.C. Meyers Vænge 15, 2450 \\ Copenhagen SV, Denmark, tvr@sbi.aau.dk
}

\begin{abstract}
This article describes testing of peel and shear resistance and airtightness of joints of air and vapour barrier systems before and after artificial aging. The testing of peel and shear resistance was based on standardised methods while the test of airtightness was a method invented for this project. The results show that while peel and shear strength increased with aging, the airtightness was significantly reduced. As these two results seem to contradict each other, the methods are discussed, especially whether the standardised tests are too far from the conditions on site or joints should be tested on other materials as well. Furthermore, weaknesses in the airtightness method is also pointed out.
\end{abstract}

Keywords: Peel Resistance, Shear Resistance, Airtightness, Artificial Aging, Air and Vapour Barrier.

\section{Introduction}

To reduce energy consumption some building regulations (e.g. BR18, 2017) require test of airtightness in newly erected buildings. Membranes are widely used to ensure the required airtightness but often their purpose is twofold; increased airtightness and reduced diffusion. Independently of whether a vapour barrier or an air barrier is needed, the tightness of the joints is crucial. Furthermore, the joints must stay tight throughout the service life of the membrane.

By joints are meant joints between two lengths of membrane and joints between membrane and other building parts. Tapes or adhesives can be used as sealants, most manufacturers sell membranes and sealants as systems, preferably including collars for pipes that may penetrate the membrane. This is a way to ensure that membrane and sealant are compatible. In Denmark, an independent company (DUKO) classifies vapour barrier systems and roofing underlays, the requirements for obtaining classification include tests of peel and shear resistance.

There are different standardised ways to test joints, e.g.:

- Peel resistance according to EN 12316-2:2013 or E DIN 4108-11:2016

- Shear resistance according to EN 12317-2:2010 or E DIN 4108-11:2016

Systems can be tested just after installation or after ageing. Although tests of airtightness are only required in new buildings, evaluation of durability requires tests of performance of aged joints. Methods for artificial aging are described by Møller and Hansen (2017), together with detailed descriptions of resistance test methods and a new way of testing airtightness.

This article describes the outcome of tests of resistance against peel and shear of nine vapour or air barrier systems before and after aging and the result of the non-standardised test of airtightness. It also discusses whether the result from standardised test methods corresponds to what can be observed on building sites and the new way of testing airtightness. 


\section{Method}

All test methods are based on the standardised methods described in ISO or DIN standards except for the test of airtightness, which has been invented for this project. To ensure a uniform pressure when taping the joints, samples for peel or shear resistance testing were placed on a plane surface and a $50 \mathrm{~mm}$ wide $2 \mathrm{~kg}$ rubber coated roller was pulled over the joint.

\subsection{Materials}

Nine air or vapour systems were selected for testing, the selection was made by contacting manufacturers and suppliers of air or vapour barrier systems. It was asked whether they would be interested in having their product tested. The characterisation of the materials as given by the manufacturers is shown in Table 1. All systems used tape for joints.

Table 1. Materials used for testing with descriptions given by the manufacturers, VB and AB denotes Vapour Barrier and Air Barrier, respectively. PE = Polyethylene, PP = Polypropylene.

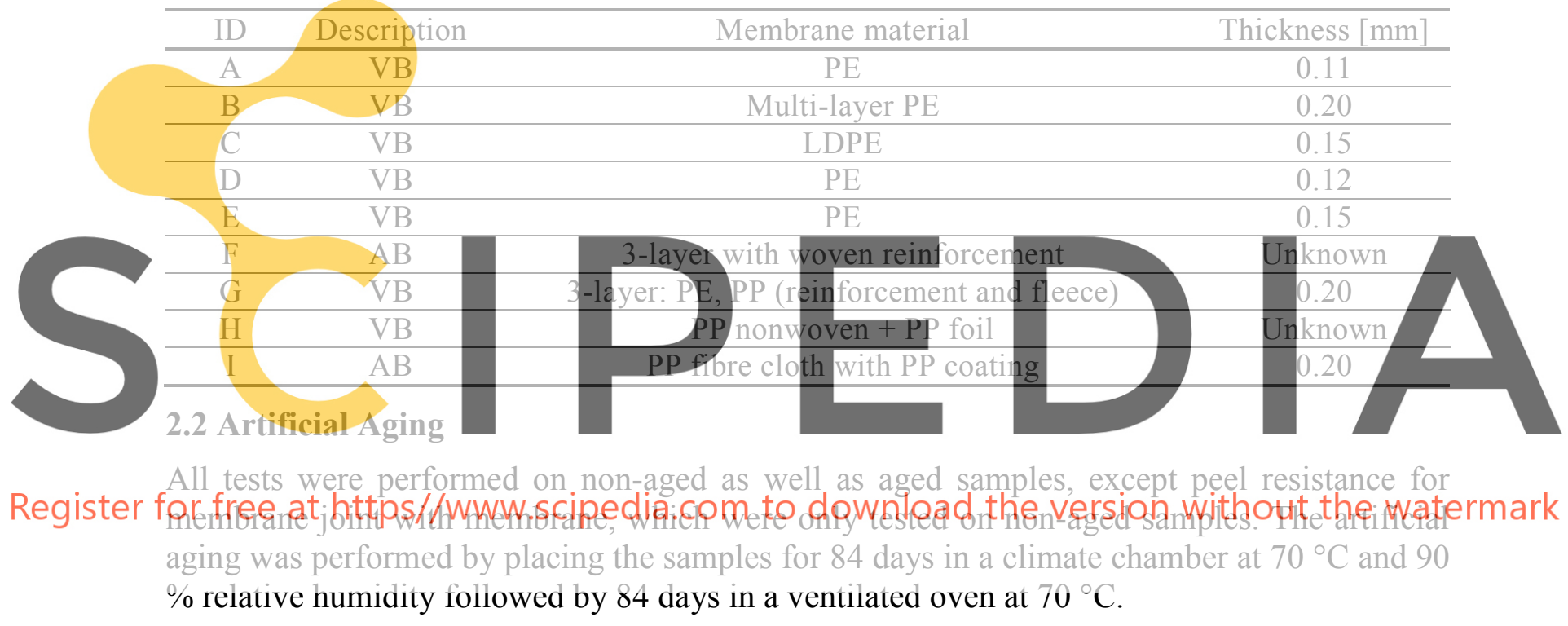

\subsection{Peel Resistance}

Peel resistance was tested on joints of two membranes and joints of membrane and aerated concrete (AAC). The tests were performed according to EN 12316-2:2013 that specifies how to test peel resistance of a joint between two pieces of a membrane. A sample was placed in a testing machine with the grips $200 \mathrm{~mm}$ apart. During testing the grips moved apart at a constant speed. The force used for peeling was recorded. The method was adjusted for the test with AAC because of the thickness of the AAC.

In addition, the speed of the tests was reduced from a separating speed for the grips from $100 \pm 10 \mathrm{~mm} / \mathrm{min}$ to $10 \pm 1 \mathrm{~mm} / \mathrm{min}$. Samples used for membrane/AAC tests were approx. 14 $\mathrm{cm}$ wide instead of the standardised $50 \mathrm{~mm}$, that were used for the membrane/membrane joints. The measured force was converted to the equivalent force for $50 \mathrm{~mm}$ samples. Figure 1 shows the principle of the tests as well as pictures from the testing. Five samples were tested for each material combination. 
$180^{\circ}$
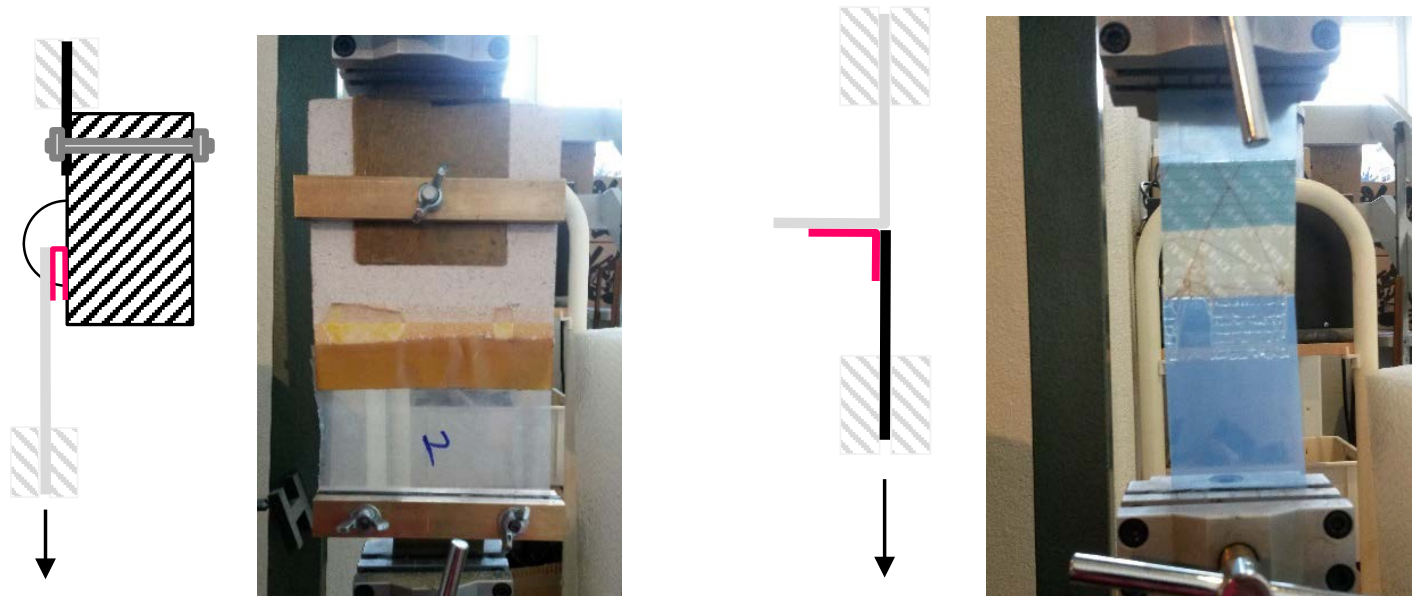

Figure 1. Test of peel resistance, sketch from the side and photo from the front. Left: Membrane taped to AAC.

Right: Two pieces of membrane taped together.

\subsection{Shear Resistance}

Shear resistance was tested on aged and non-aged joints of membrane/membrane (see Figure 2) and according to EN 12317-2:2010. Similar to the peel test, the ends of the samples were placed in the grips of a testing machine with a constant separating speed and the shear strength was recorded. The separating speed was reduced from $100 \pm 10 \mathrm{~mm} / \mathrm{min}$ to $10 \pm 1 \mathrm{~mm} / \mathrm{min}$.
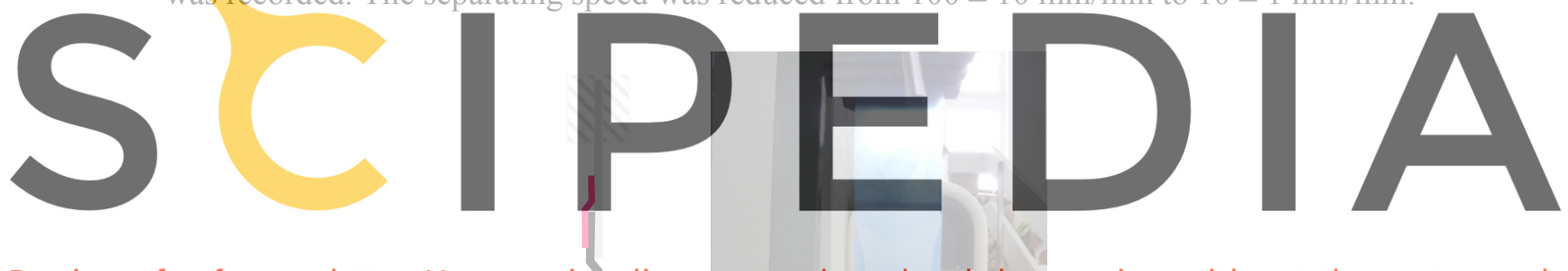

Register for free at https//www.scipedia.com to download the version without the watermark

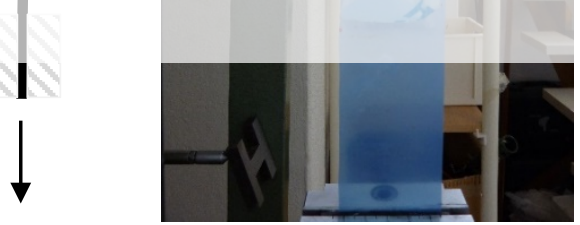

Figure 2. Test of shear resistance, sketch from the side and photo from the front.

\subsection{Test of Airtightness}

The test of airtightness was not a standard test but a test especially invented to simulate conditions in an older attic where it would be difficult to establish an airtight barrier. The aim was to test airtightness before and after artificial aging. The method is described in (Møller and Hansen, 2017). In short, it consisted of a wooden frame supplied with angled boards and a pipe in the middle. The inside of the frame was lined with the membrane to be tested and fixed to the frame with the system's tape. To secure airtightness around the pipe the system's collars were used and the pipe sealed. The frame was placed in a box leaving a small space between membrane and box, see Figure 3. It was ensured that the frame was airtight and so was the 
connection between box and frame. Through a hole in the box a ventilator created a pressure difference between box and frame. The flow necessary to obtain pressurisation of $10,22,34$, 46, 58, 70 and $82 \mathrm{~Pa}$ was recorded. The test was repeated three times and again three times with the same negative pressure differences. By linear regression, the results from the different pressure differences were combined to a single value for a pressurisation of $50 \mathrm{~Pa}$. The test was inspired by the blower door test (EN/ISO 9972: 2015). After 164 days of artificial aging, the tests were repeated. One frame of each system was tested.
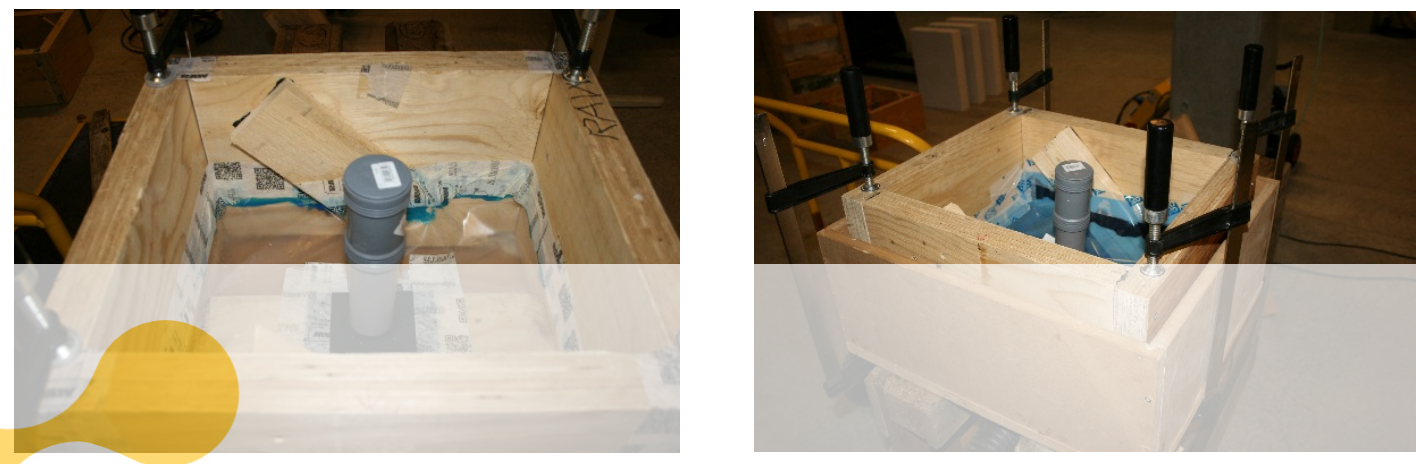

Figure 3. Test equipment for test of airtightness. Left: wooden frame with lining of membrane taped to the frame, pipe with collar in the middle. Right: wooden frame placed in box, a ventilator created a pressure difference between frame and box through a hole in the box (not visible on photo).
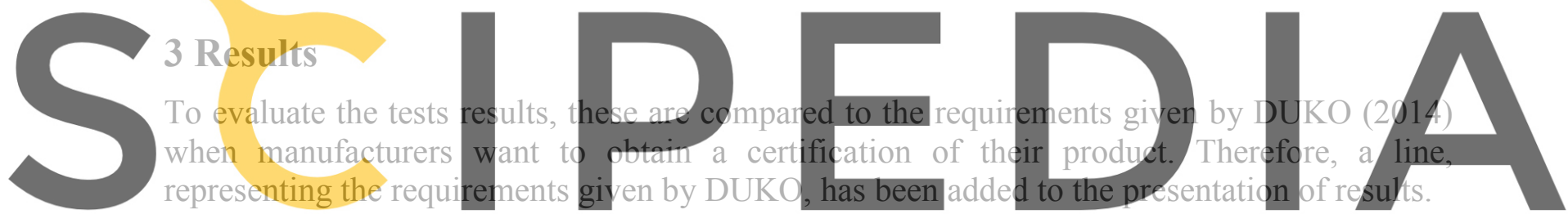

Register for free at heststps//www.scipedia.com to download the version without the watermark The DUKO requirements for non-aged joints of membrane/membrane and membrane/AAC is

$10 \mathrm{~N} / 50 \mathrm{~mm}$. There are no requirements for aged joints. The results of the peel resistance tests are shown in Figure 4. All systems fulfilled the DUKO requirements. Except for system B, all membrane/ACC became stronger with aging. All non-aged membrane/membrane joints, except for system $\mathrm{C}$, were more than $20 \%$ stronger than non-aged membrane/ACC joints.

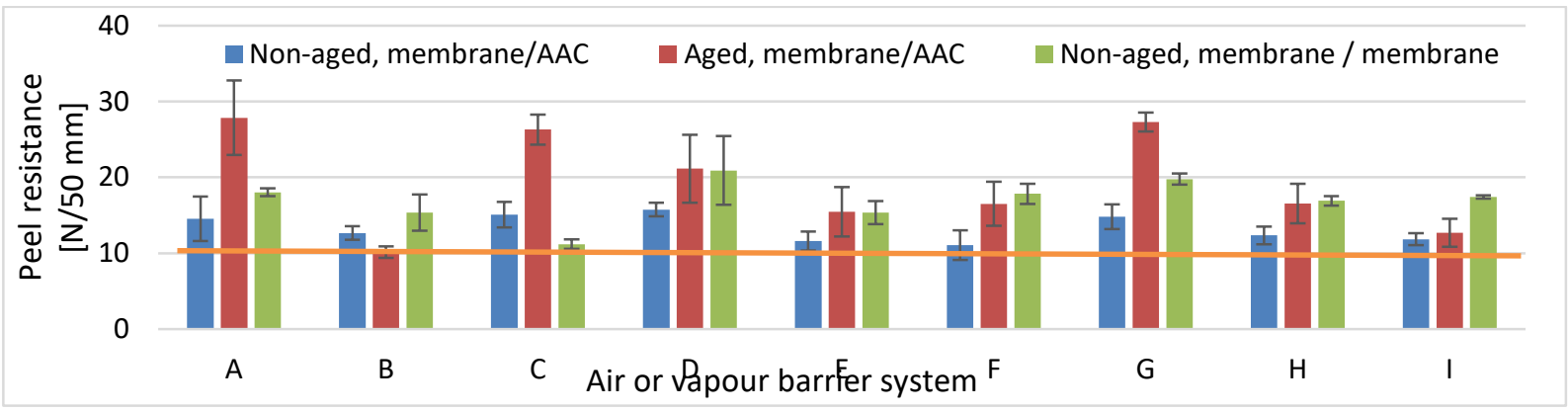

Figure 4. Result of test of peel resistance, average of five samples, with standard deviations. The orange line marks the DUKO requirements for non-aged joints, there are no requirements on aged joints. 
Tapes consist of an adhesive and a carrier layer. As shown in Figure 5 there were different places where the adhesive could fail; either the bonding to AAC or to the carrier layer. Where the adhesive stayed showed where the best bonding took place.
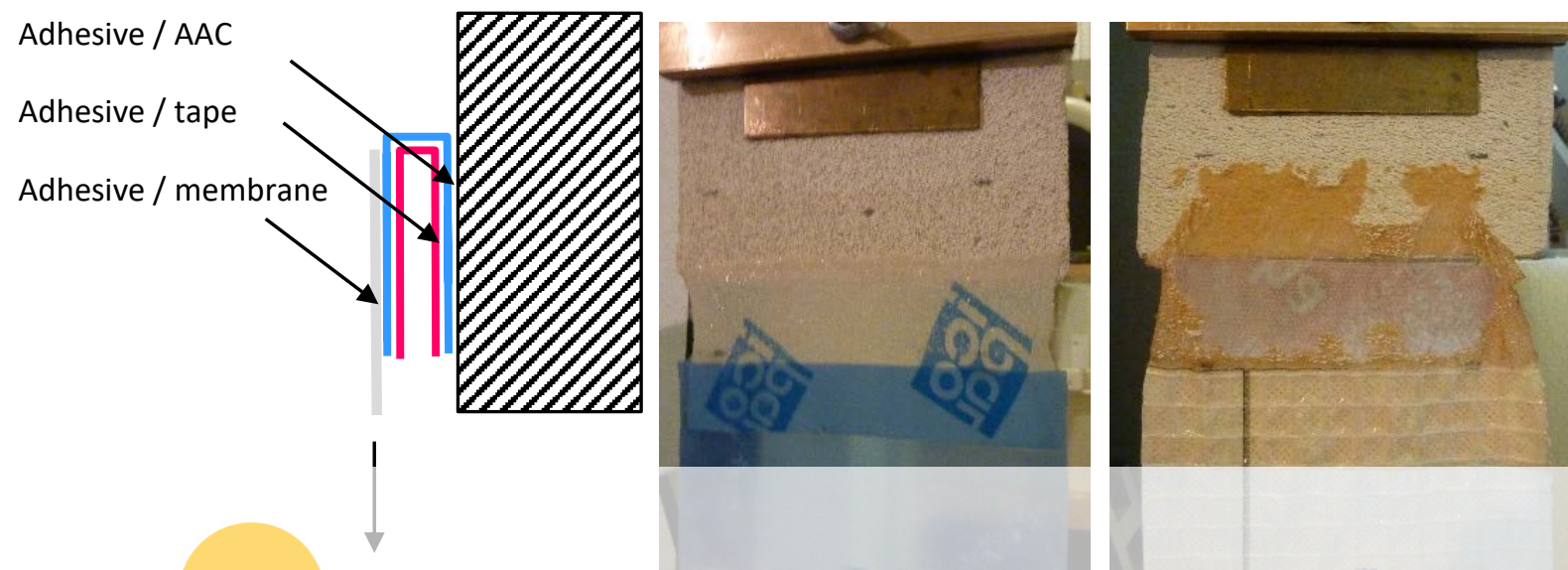

Figure 5. The failure of the adhesive could appear in different places, the sketch shows three possibilities in membrane/AAC connections. The photos show examples, Left: Failure between adhesive and AAC (very little adhesive left on AAC). Right: Failure between adhesive and tape as the adhesive left the carrier layer of the tape.

In some tests, the failure was not clearly between two layers, but parts of the adhesive would

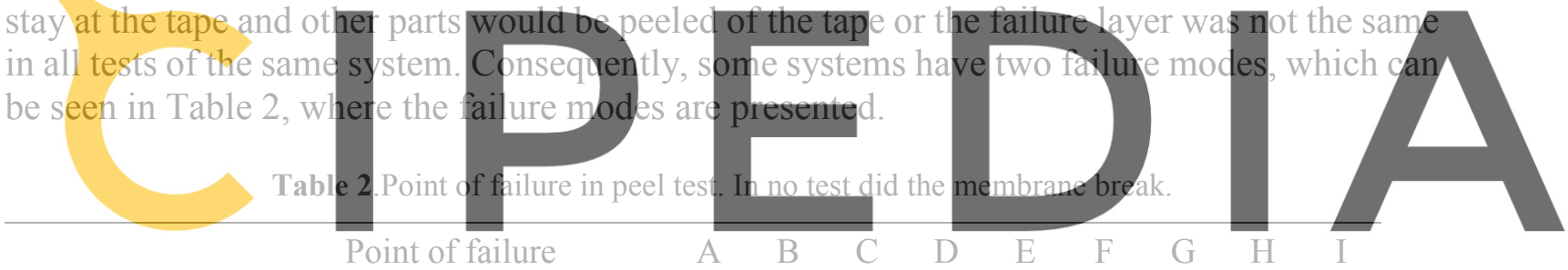

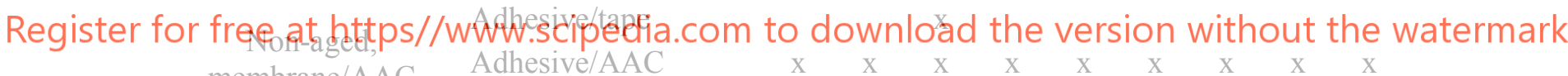
membrane/AAC Adhesive/membrane

\begin{tabular}{|c|c|c|c|c|c|c|c|c|c|c|}
\hline \multirow{3}{*}{$\begin{array}{c}\text { Aged, } \\
\text { membrane/AAC }\end{array}$} & Adhesive/tape & $\mathrm{x}$ & $\mathrm{x}$ & & \multirow{3}{*}{$\mathrm{x}$} & \multirow[t]{3}{*}{$\mathrm{x}$} & \multirow[t]{3}{*}{$\mathrm{x}$} & \multirow{3}{*}{$\begin{array}{l}x \\
x\end{array}$} & \multirow[t]{3}{*}{$\mathrm{x}$} & \multirow[t]{3}{*}{$\mathrm{x}$} \\
\hline & Adhesive/AAC & $\mathrm{x}$ & & & & & & & & \\
\hline & Adhesive/membrane & & & $\mathrm{x}$ & & & & & & \\
\hline \multirow{2}{*}{$\begin{array}{c}\text { Non-aged, } \\
\text { membrane/membrane }\end{array}$} & Adhesive/tape & $\mathrm{x}$ & & & & $\mathrm{x}$ & $\mathrm{x}$ & & $\mathrm{x}$ & $\mathrm{x}$ \\
\hline & Adhesive/membrane & $\mathrm{x}$ & $\mathrm{x}$ & $\mathrm{x}$ & $\mathrm{x}$ & & & $\mathrm{x}$ & $\mathrm{x}$ & \\
\hline
\end{tabular}

\subsection{Shear Tests}

The results of the shear tests are shown in Figure 6, all systems fulfilled the DUKO requirements. The non-aged samples of system A did not come apart; the membrane, however, was stretched to more than the double of its length, without enhancing the force of the machine. In the rest of the systems, the adhesive did not stick to the tape. In the aged samples, the tape broke in system $A$ and $G$, in the other systems the adhesive did not stick to the tape. 


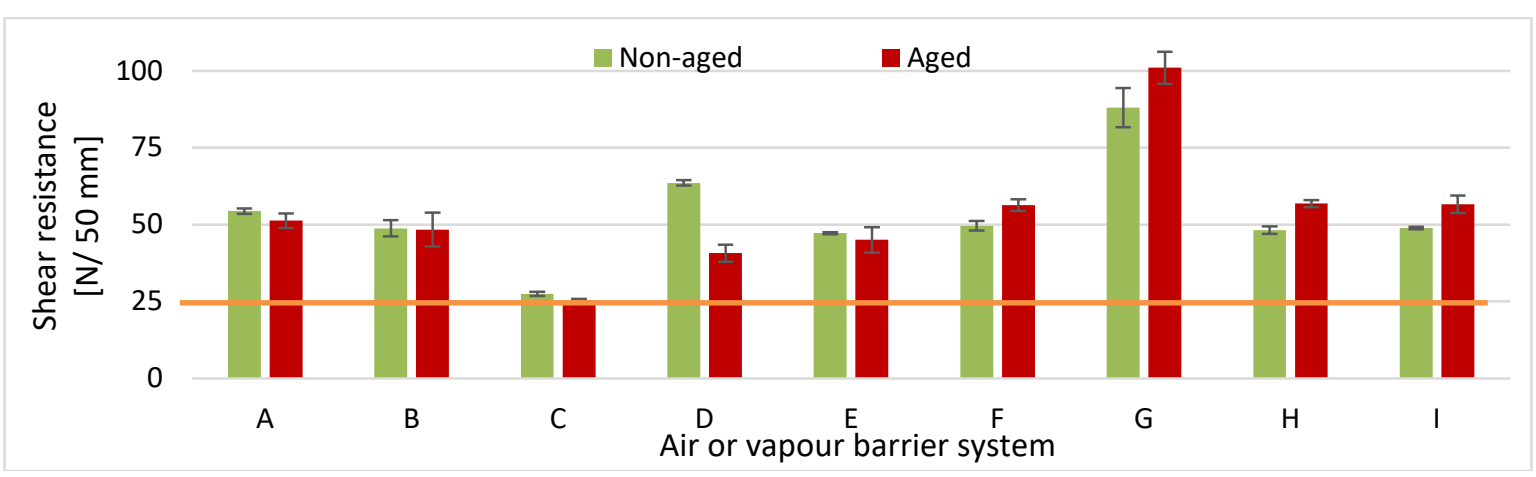

Figure 6. Shear strength, average of 5 samples with standard deviations. Orange line: DUKO requirements for non-aged and aged joints.

\subsection{Airtightness}

The results of the airtightness tests are shown in Figure 7. All systems needed higher air flow after aging, i.e. all systems were leakier after aging, typically 2-3 times more than before aging.
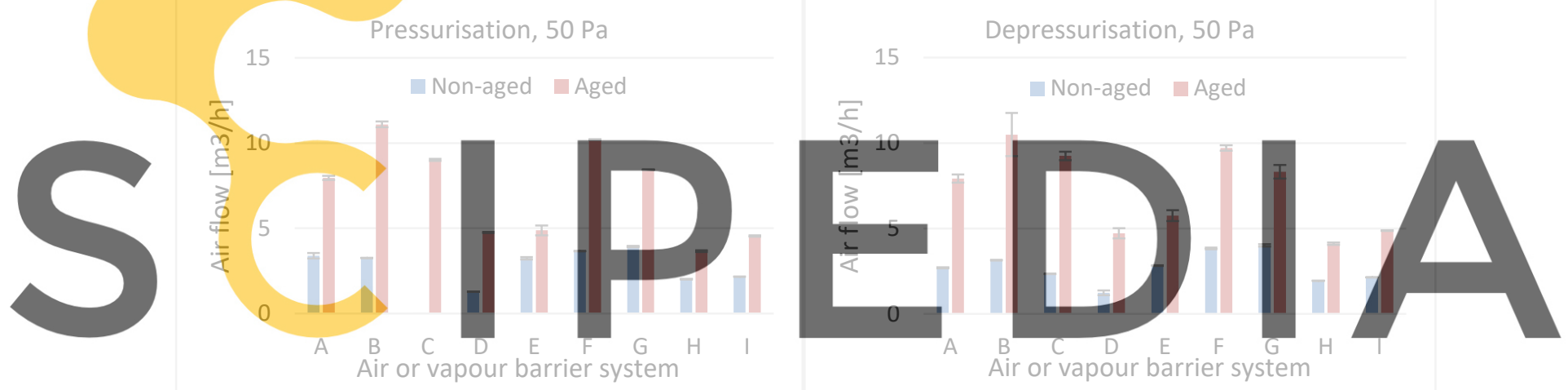

Register for free at https/fwww scipedia.com to download the version without the watermark With standard deviations.

\section{Discussion}

Whether the aging method is the most relevant will not be discussed here, as this method has been discussed by Møller and Hansen (2017). Furthermore, there is no clear picture of which systems perform best, consequently, the discussion is limited to general results and the methods.

\subsection{Testing of Peel and Shear Resistance}

Although the testing of peel and shear resistance are two different tests, there are many similarities between the results, therefore, these are discussed collectively.

It was expected that peel and shear strength would decrease because of aging. However, the results contradict this; except for system B, peel strength on AAC was generally enhanced and shear strength on membrane/membrane was enhanced or only reduced by less than $10 \%$ in all cases except system $D$ where the shear strength was reduced by more than $1 / 3$.

This is surprising, as practitioners have reported how some tapes, with time lose their ability to adhere to membranes, and from that generalised to all types of surfaces. Unfortunately, these 
statements have not been verified systematically, and are only built on specific cases that experienced craftsmen have come across. Change of bonding may vary with aging and be surface/material dependent. Therefore, testing with a larger variety of surfaces seems needed.

However, it also raises the question whether the tests can predict the behaviour of the systems on site. The samples were made under ideal conditions: The joints were assembled on a plane horizontal support with a $2 \mathrm{~kg}$ roller under relatively clean laboratory conditions; this ensured the reproducibility of the test. Unfortunately, this may be in contradiction to conditions on site, where there should be a solid support, but the surface may not be plane and clean, the pressure used on the tape is not well defined. Hence, air leakage may not only be related to aging but to bad adhesion in the first place and consequently more sensible to aging than the tests foresee. It underlines the importance of correct workmanship, but questions the relevance of the tests.

In the peel tests of non-aged samples with AAC the adhesive was generally peeled of the AAC, while in the aged test the adhesive was more often peeled of the tape; apparently bonding to the AAC grew with aging. It is not clear why; maybe the heat decreased the viscosity of the adhesive, consequently, the adhesive could penetrate the pores of the AAC and thereby enhance the bonding. Maybe the outcome would have been differently if beech had been used instead of AAC, as prescribed in E DIN 4108-11:2016, the pores in beech are much finer than in AAC.

In the aged samples and most of the membrane/membrane joints, the failure occurred between the adhesive and the carrier layer of the tape. This means that it is not a problem to ensure bonding to membranes in shear tests or to AAC in general; the weak spot is in the tape itself, a better tape would be one where the adhesive bonds better to the carrier lay

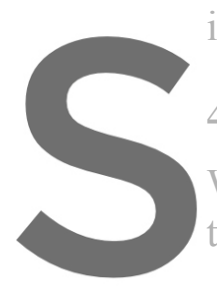

4.2 Testing of Airtightness

While the peel and shear tests are standardised, therefore relevant not or

The results of the airtightness tests were rep
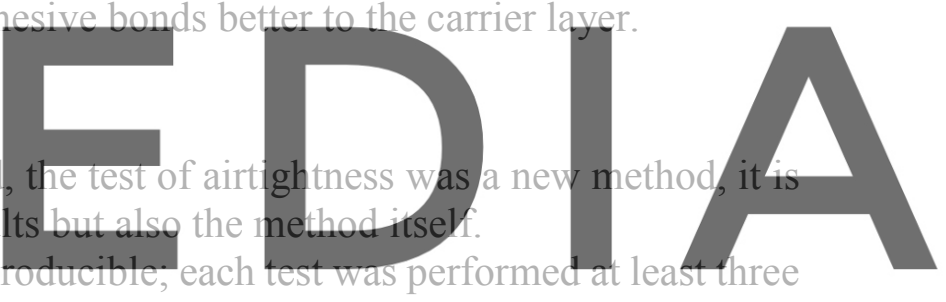

times and the results were very close to each other; apparently, tests with pressure difference of

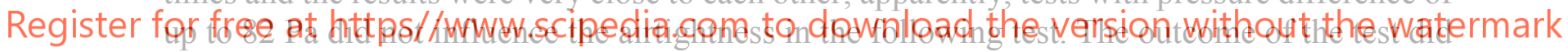
also not depend on the operator, something that was also tested.

Contrary to the peel and shear tests, the testing of the airtightness showed a significant reduction caused by aging. Probably the uneven support made it impossible to make as perfect joints as in the standardised plane test samples; possibly tension in the joints caused leakage if these tensions opened the joints over time. The test was designed to simulate realistic conditions in a building and - contrary to the standardised peel and shear tests - the results agreed with statements from practitioners. The test might therefore be relevant. Unfortunately, the samples were not tightened to the same level of tightness level before testing, but only tightened to a level, where it was possible to obtain the needed pressure difference. In many cases additional tightening had to be done immediately before testing the non-aged samples. Consequently, the test only shows the influence of ageing of systems with a tightness above a certain level. Artificial aging seemed to be important, however, it is possible that the release of tension in the joints happened within relatively short time. The testing should probably have been performed more than $24 \mathrm{~h}$ after final tightening just as the peel and shear tests were. Other test methods that involve membranes, e.g. test of radon membranes, require a relaxation period of at least 40 hours after installation (Rasmussen and Cornelius, 2017). 
DUKO (2014) has a method of testing airtightness that involves a mock-up of a wooden framework resembling a $12 \mathrm{~m}^{2}$ wooden building. It is tested for airtightness twice with one week apart, but no artificial aging. By comparing the two tests methods, it might be possible to determine if artificial aging is important for the test.

\section{Conclusion}

The tested systems all fulfil the requirements for obtaining a DUKO certification on peel and shear resistance. In peel tests of aged samples on AAC and almost all shear tests, the weak layer was at the intersection between carrier layer of the tape and the adhesive, thus, improvement of the peel resistance should be an improvement of the tape itself not the bonding to AAC.

Surprisingly, the peel resistance increased with aging for taped joints to AAC, and shear resistance increased generally. Contrary to this, the test of airtightness showed significant loses in airtightness after aging performed in a wooden box. This raises the question whether the standardised tests of peel and shear resistance are performed under conditions that are too far from the conditions on site and therefore irrelevant. Additionally, it may be necessary to test on more surfaces than only membrane and ACC, e.g. wood.

The airtightness test was an attempt to find a different but relevant and reproductive test method. The method still needs to be improved, and compared with other test methods, but the result seemed to be reproductive and in concordance with experience from practice.

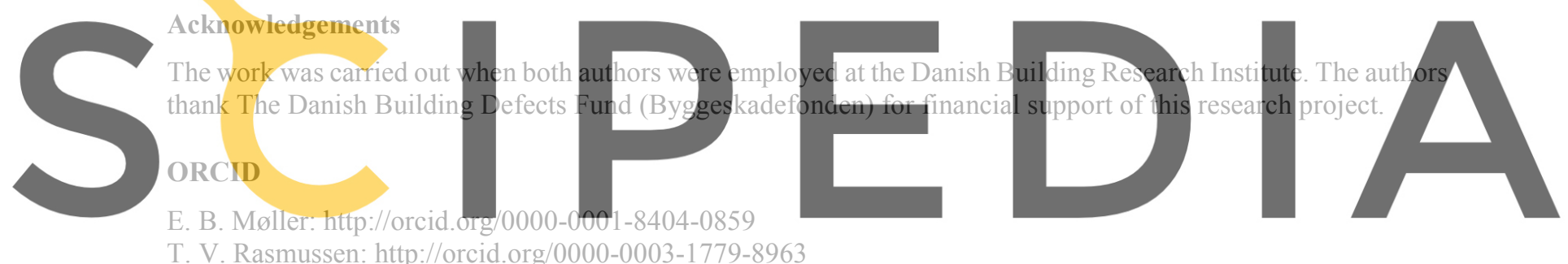

Register for free at https//www.scipedia.com to download the version without the watermark References

BR18 (2017). Bekendtgørelse af offentliggørelse af bygningsreglement 2018 (Danish building regulations, in Danish), Trafik-, Bygge- og Boligstyrelsen, Copenhagen, Denmark.

DUKO (2014) Information on www.duko.dk: Krav til dampspærresystemer under DUKO - Dampspærre- og Undertagsklassifikationsordning (in Danish, authors translation: Requirements on vapour barrier systms under DUKO): https://duko.dk/userfiles/Klassifikationskrav_dampspaerresystemer-udgave01_20140414.pdf

E DIN 4108-11 (2016). Entwurf: Wärmeschutz und Energie-Einsparung in Gébäuden - Teil 11: Mindestanforderungen an die Dauerhaftigkeit von Klebeverbindungen mit Klebebändern und Klebemassen zur Herstellung von luftdichten Schichten (in German). E = Entwurf i.e. draft, not implemented yet.

EN/ISO 9972: (2015) Thermal performance of buildings - Determination of air permeability of buildings - Fan pressurization method

EN 12316-2: (2013) Flexible sheets for waterproofing - Determination of peel resistance of joints - Part 2: Plastic and rubber sheets for roof waterproofing

EN 12317-2 (2010) Flexible sheets for waterproofing - Determination of shear resistance of joints - Part 2: Plastic and rubber sheets for roof waterproofing

Møller, E.B. and Hansen, T. (2017). Artificial aging of air and vapour barriers. In Proceedings of the XIV International Conference on Durability of Building Materials and Components, Ghent, Belgium, 285, 1-12.

Rasmussen, T.V. and Cornelius, T. (2017). Radon barrier: Method of testing airtightness - 2. Edition. In Proceedings of 11th Nordic Symposium on Building Physics, NSB2017, 11-14 June 2017, Trondheim, Norway. 